\title{
Towards Experimental Measurement of Methane Adsorption Isotherm in Shale Reservoirs
}

\author{
Razieh Solatpour ${ }^{1}$, Apostolos Kantzas ${ }^{1}$ \\ ${ }^{1}$ Chemical and Petroleum Engineering department, Schulich school of Engineering, University of Calgary \\ 2500 University Drive NW, Calgary, Alberta, T2N 1N4 \\ razieh.solatpour1@ucalgary.ca; akantzas@ucalgary.ca
}

\begin{abstract}
Unconventional petroleum resources, especially shales, constitute an increasing frontier of reserves additions as conventional production declines. This research is a study to investigate the interactions between shale rocks with gaseous hydrocarbons and mainly uses NMR logging which is a powerful tool to obtain in-situ rock and fluid properties of hydrocarbon reservoirs. In this study, a novel procedure is developed to quantitatively estimate the excess adsorption of gaseous hydrocarbon on shale gas reserves using direct measurements of an in-house built NMR setup. NMR experiments are conducted to measure NMR-porosity, relaxation distribution, and pore size distribution. These measurements are compared at different pressures in porous media with different adsorption capacity. As a result, adsorbed hydrocarbon gas content is estimated, and finally, adsorption isotherm is presented. Additional experiments such as gas expansion porosity and gravimetric adsorption are conducted to validate the new NMR method. In this research, for the first-time LowField NMR relaxometry with frequency close to logging tools is used for quantitative determination of adsorption isotherms of methane in shale reservoirs. These measurements help estimate the gas content and differentiate between adsorbed and free gas in porous media, paving the way for studies such as natural gas storage in shale rock, $\mathrm{CO}_{2}$ sequestration, and tight enhanced recoveries such as gas flooding and cyclic solvent injection.
\end{abstract}

Keywords: Experimental, Adsorption, Adsorption isotherm, Shale.

\section{Introduction}

Low-Field NMR has been widely used in energy research including investigations of methane in shale rocks and hydrogen storage in carbon nanotube and other nano-porous materials. In any porous media, NMR technique is able to determine the fluid properties such as viscosity, chemical composition, and fluid-pore surface interactions. In addition, the geometrical properties of the porous matrix such as tortuosity, surface-to-volume ratio, and diffusive permeability may also be determined. NMR investigations of fluids in porous media are generally performed through measurements of relaxation times and diffusion coefficients [1]. NMR has broad applications in the petroleum industry, because it has the advantage of fast detection, no damage to the sample, and no geometry requirement to the sample for testing [2]. However, its application to gases, has been limited by poor signal to noise ratio, a consequence of the low-density medium [3].

There are very few literature data on gaseous hydrocarbon NMR measurements in porous media and they are collected mainly using High-Field NMR [1], [4], and [5]. The issue is due to the low number of protons in gas phase. In this study, first objective is to investigate the possibility of detecting gas by Low-Field NMR. To achieve this, increasing the pore volume of the porous media and also increasing the detecting area (sweet spot) of the NMR instrument is implemented. These measurements are beneficial in shale gas reservoir estimation and tight enhanced recovery which are highly dependent on hydrocarbon adsorption estimation.

Gas shales are organic rich mudstones characterized by the presence of nanometer size organic kerogen pores, hosting natural gas. The methane molecules in the nanopores coexist in two phases: free gas that has bulk like properties and adsorbed gas that undergoes strong interaction with the pore walls [1]. Papaioannou et al., conducted adsorption measurements using High-Field NMR, $400 \mathrm{MHz}$. They used zirconium Vycor nanoporous glass tubes with the size of $3 \mathrm{~mm}$ diameter and $92 \mathrm{~mm}$ length as the porous media. The measurement of methane adsorption using High-Field NMR, $400 \mathrm{MHZ}$, can be find in literature [4]. Yao et al. used Low-Field NMR, 23.15 MHz, to measure methane adsorption on coal [5]. However, comparing to logging tools, $23.15 \mathrm{MHz}$ has a highly stronger frequency. In this study, for the first time, Low-Field NMR, $2.87 \mathrm{MHz}$, is used to measure adsorption of light hydrocarbon on activated carbon. The resonance frequency and NMR parameters used 
in this study is close to those of the logging tools. According to the literature, this is the first time low-filed NMR technique is used for quantitative measurements of light hydrocarbon adsorption in shale media.

Liu et al., published an article in 2017 claiming that for the first time, they used NMR to investigate the dynamic interactions between adsorbed methane and injected $\mathrm{CO}_{2}$ [6]. However, they used competitive adsorption principles, and their work is different than this study in a few ways. The most important difference is that they did not present the adsorption isotherm which will be presented in this study. The strength of the magnet they used is $23.15 \mathrm{MHz}$. In this study we use $2.87 \mathrm{MHz}$ NMR. Liu et al., used fine powder of shale which eliminates the effect of pore size distribution. In this study, we use activated carbon pack (AC-pack) which is a proxy for kerogen and investigate the pore size distribution [7]. Based on an experimental study on Devonian shale, the shape of the shale adsorption isotherm is best explained by adsorption on carbon [8].

Other than High-Field NMR, the gaseous hydrocarbon adsorption can be measured by a gravimetric method which is very sensitive and very expensive [9]. This study proves that Low-Field NMR is able to detect signals of the gaseous phase which is achieved by improving the NMR setup. This method is a non-destructive and fast method in deciphering fluid/rock interactions in tight rocks and shales. Low-Field NMR is close to logging tools, which opens the door to implement such measurements in logging tools.

In this study, we use Low-Field NMR technique to measure the signals of methane at pressures up to 1500 psia. The NMR measurements are being conducted at bulk form and in sand pack and AC-pack. $T_{2}$ distribution, $T_{2 \mathrm{gm}}$, total amplitude, NMR porosity, and adsorption are being measured. NMR porosity and adsorption are being compared with independently measured gas expansion porosity and gravimetric adsorption. The effect of pressure on relaxation distribution curve, $\mathrm{T}_{2 \mathrm{gm}}$, and methane adsorption is investigated. To validate the method, a cross plot of gravimetric and NMR adsorption measurements is presented.

\section{Experimental materials and methods}

All the experiments conducted at atmospheric pressure and room temperature. The temperature of the sample inside the NMR setup was controlled and recorded. The schematics of the experimental setup showed in the Figure 1.

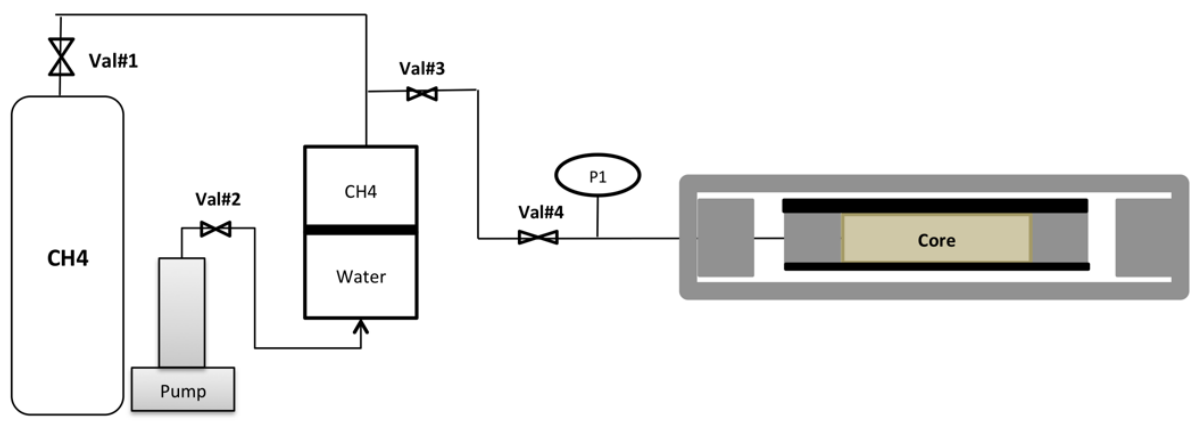

Fig. 1: Schematics of the experimental setup.

A $2.87 \mathrm{MHz}$ NMR apparatus with the Time Echo of $0.0002 \mathrm{~s}, 8000$ Echoes, 64 trains, and $15 \mathrm{~s}$ waiting time used for all set of experiments. Sand with the density of $2.64 \mathrm{~g} / \mathrm{ml}$ and 50 mesh size used to build the sandpacks. The adsorption properties of light hydrocarbons on activated carbon pack (AC-pack) are measured at pressures lower than 1500 psia using nuclear magnetic resonance. Activated carbon obtained from American Chemical Company Inc. with the mesh size ranges from 4 to 12 . Methane gas obtained from PRAXAIR at the purity $99.99 \%$. The methane density at $23.5^{\circ} \mathrm{C}$ temperature and different pressures obtained from NIST WebBook. Methane critical pressure at room temperature is 667.06 psia. A peek core holder used in this study for bulk, sandpack, and AC-pack measurements. For 
comparing these porous media, the amplitude normalized against the pore volume. This is not a closed system and to increase and decrease the pressure, gas injected to or released from the core holder.

\subsection{Gas expansion porosity of sandpack and AC-pack}

First, the peek core holder is filled with the sand. The sandpack is vacuumed and its weight measured. Porosity is calculated from gas expansion method, which is based on Boyle's law. The Boyle's gas law equation states that at constant constant temperature, the product of pressure and volume is a constant for a given mass of confined gas. Helium used in gas in gas expansion porosity measurements of AC-pack.

\section{Experimental result and discussion}

\subsection{NMR measurements of bulk methane}

Bulk NMR measurements are conducted and Amplitude Index (AI) of methane is calculated. This AI will be used later to convert the NMR signals to methane mass. For details on experimental procedure please refer elsewhere [11], [12]. Using the following equation, gravimetric mean of $\mathrm{T}_{2}$ is experimentally calculated at different pressures.

$$
\mathrm{T}_{2 \mathrm{gm}}=\operatorname{EXP}\left(\frac{\sum \mathrm{A}_{\mathrm{i}} \operatorname{Ln}\left(\mathrm{T}_{2 \mathrm{i}}\right)}{\mathrm{A}_{\mathrm{T}}}\right)
$$

Where $A_{i}$ is the amplitude at each $T_{2}$ and $A_{T}$ is the total amplitude. Figure 2 demonstrates the $T_{2}$ relaxation distribution and $\mathrm{T}_{2 \mathrm{gm}}$ of bulk methane as a function of pressure. As expected, there is only one relaxation peak and it relaxes around 1000 $\mathrm{ms}$. As the pressure decreases, the area under the peak decreases and shifts to the faster times. Because at lower pressures, the effect of diffusion is more significant.
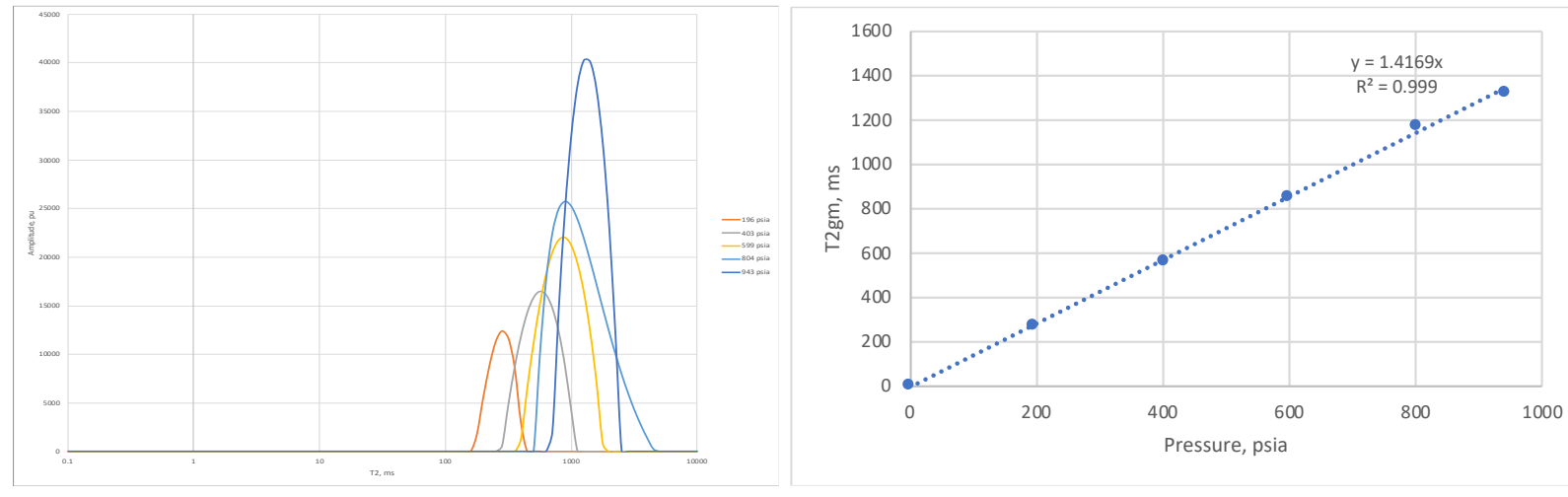

Fig. 2: NMR relaxation distribution and $\mathrm{T}_{2 \mathrm{gm}}$ of bulk methane at different pressures.

No phase transition effects are observed across the critical pressure $\left(\mathrm{P}_{\mathrm{c}}=667.06 \mathrm{psia}\right)$ as indicated by $\mathrm{T}_{2 \mathrm{gm}}$ graph. This is consistent with the results from [1]. The change in relaxation time across the $\mathrm{P}_{\mathrm{c}}$, might be noticeable above the critical temperature [1].

\subsection{NMR measurements of methane in sandpack}

Methane is injected into the sandpack with the injection rate of $1000 \mathrm{ml} / \mathrm{hr}$. Based on the recorded pressure and time, the injected volume is calculated. The same NMR parameters used in the bulk measurements are also used in the sandpack measurements. Diffusion effects are confirmed to be negligible at short time echoes [1]. Figure 3 shows the $T_{2}$ relaxation distribution of methane in sandpack as a function of pressure. This graph is a representation of pore size distribution. There are two different pore sizes in this sandpack. The faster peak relaxes between $1 \mathrm{~ms}$ and $20 \mathrm{~ms}$ while the slower one relaxes 
between $20 \mathrm{~ms}$ and $200 \mathrm{~ms}$. The majority of methane relaxes at the slower peak, which is consistent with the uniform pore size of the sandpack; and compared to the bulk methane, pore methane relaxes faster.

The $\mathrm{T}_{2}$ relaxation distribution of methane in sandpack at pressures up to 1000 psia consists of two peaks. The fast is between $2 \mathrm{~ms}$ and $10 \mathrm{~ms}$ and the slow peak is between $30 \mathrm{~ms}$ and $200 \mathrm{~ms}$. As the pressure increases the slow relaxing shifts to the right and the fast-relaxing peak shifts to the left. No signal related to bulk methane observed in the relaxation distribution. After the NMR measurements are conducted at the highest pressure, it is decided to measure the NMR signals at decreasing pressure mode. Methane is released in discrete steps and NMR measurements are conducted at each step. This step is taken to find if there is any discrepancy between signals from increasing and decreasing pressure mode. Because there is no adsorption of methane in the sandpack, by using the ideal gas equation of state, the total amplitude versus mass can be converted to the total amplitude versus pressure graph. The estimated pressure is calculated from the mass-balance methane mass and the ideal gas law. The total amplitude versus pressure graph can also be generated from experimental results. There is a good match between experimental results at both increasing and decreasing modes. The estimated pressure line also matches properly with the experimental results.

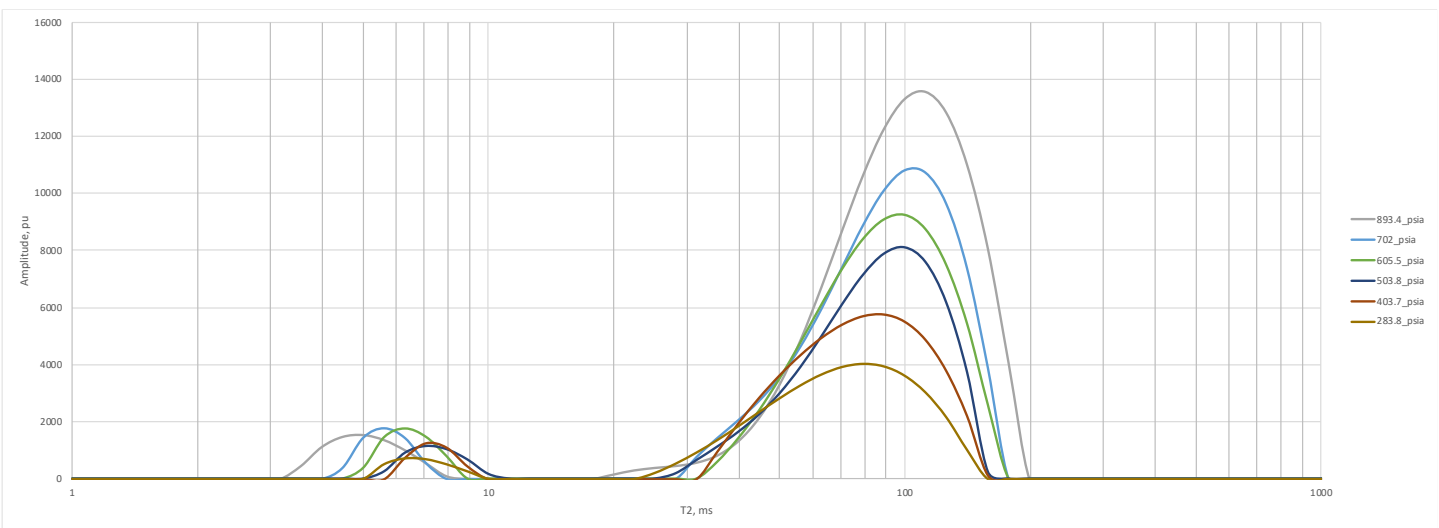

Fig. 3: $T_{2}$ relaxation time of methane in sandpack as a function of pressure.

\subsection{NMR measurements of methane in activated carbon pack}

Methane is injected to the AC-pack with the injection rate of $1000 \mathrm{ml} / \mathrm{hr}$. The pressure of the system is increased to 909 psia and then connection valve is closed. At this stage, pressure dropped because methane was adsorbed on the activated carbon and the pressure is decreased. Because the core holder is packed loosely with activated carbon, this pressure drop cannot be related to the diffusion of methane inside the AC-pack. When the pressure is stabilized, NMR measurements are conducted. Then the connection valve is opened, and methane is released to 596 psia. Then the valve is closed, and pressure is recorded. The pressure starts to build up because a partial of adsorbed methane is released. After pressure is stabilized, the NMR measurements are acquired. These steps are repeated until all of methane is released from the AC-pack. Figure 4 Left shows the recorded pressure in this process. Note the increase in pressure after each pressure drop step. 

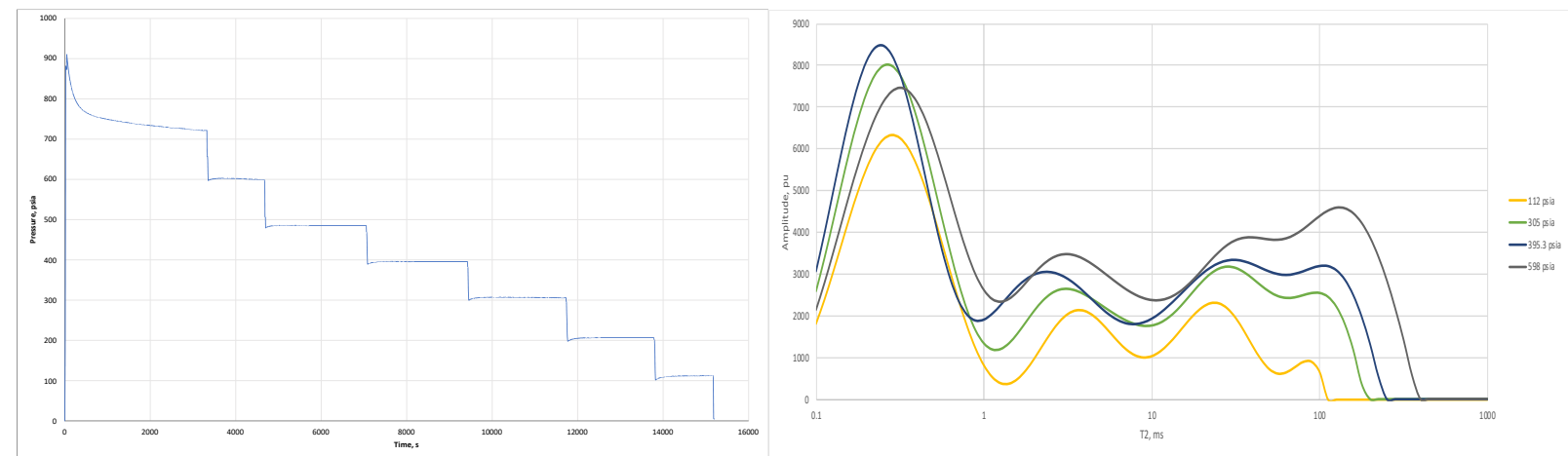

Fig. 4: Left) Pressure versus time of Methane in $\mathrm{AC}$ at decreasing pressure mode. Right) $\mathrm{T}_{2}$ relaxation distribution of methane in methane in AC-pack as a function of pressure.

Figure 4 Right shows the $\mathrm{T}_{2}$ relaxation distribution of methane in AC-pack as a function of pressure. This graph is a representation of pore size distribution. There are 4 peeks in the distribution curves. There are peaks faster than $1 \mathrm{~ms}$ which are related to the absolute adsorption of methane on activated carbon. Figure 4 Right clearly shows the increase in amplitude while the pressure increases. Peaks faster than $10 \mathrm{~ms}$ shift to the left with increase in pressure and the peaks slower than 10 ms shift to the right with increase in pressure. This is consistent with the results from the sandpack.

\subsection{Comparison of methane signals at bulk, sandpack, and AC-pack}

Figure 5 compares the relaxation distribution of methane at 400 psia pressure in bulk, sandpack, and AC-pack. Bulk methane is the slowest to relax. Methane in the sandpack does not show any adsorption, i.e. no peaks lower than $1 \mathrm{~ms}$. Methane in the AC-pack has the fastest relaxation time due to adsorbed methane. Comparing to sandpack pore size distribution, in AC-pack, the peaks are connected and there is not a distinct border between them. The total range of $\mathrm{T}_{2}$ is wider in the AC-pack. There are peaks faster than $1 \mathrm{~ms}$ and slower than $200 \mathrm{~ms}$ in AC-pack which does not exist in the sandpack relaxation curve. These differences are related to the pore size distribution and adsorption of the activated carbons. $\mathrm{AC}$ mesh sizes are between 5 to 12 which is much bigger than sand size. Therefore, pore sizes are bigger and more connected in AC-pack. Also, AC adsorbs methane while sand does not. The adsorbed methane relaxes faster than $1 \mathrm{~ms}$.

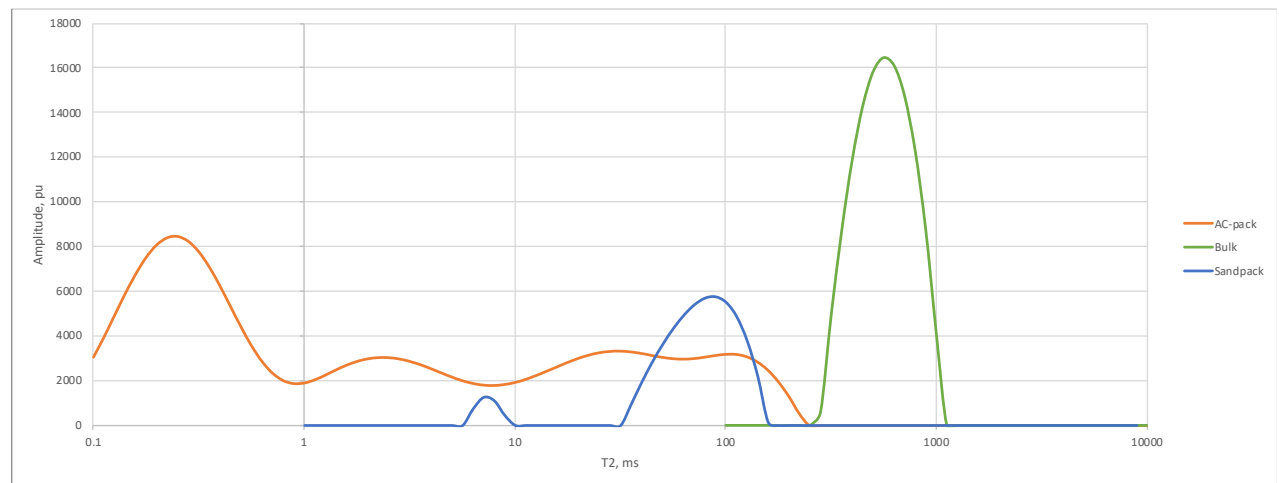

Figure 2: $\mathrm{T}_{2}$ relaxation distribution of $\sim 400$ psia methane in bulk, sandpack, and AC-pack.

The gravimetric mean of $T_{2}$ is experimentally measured at different pressures is calculated by equation 1. In Figure 6 Left, the $T_{2 \mathrm{gm}}$ of methane in sandpack and AC-pack are compared. At each pressure, the $\mathrm{T}_{2 \mathrm{gm}}$ of the AC-pack is much lower than the $\mathrm{T}_{2 \mathrm{gm}}$ in sandpack. The reason is that in AC-pack, the peak assigned to the adsorbed methane, will shift $\mathrm{T}_{2 \mathrm{gm}}$ to the left, closer to the faster relaxation times. 

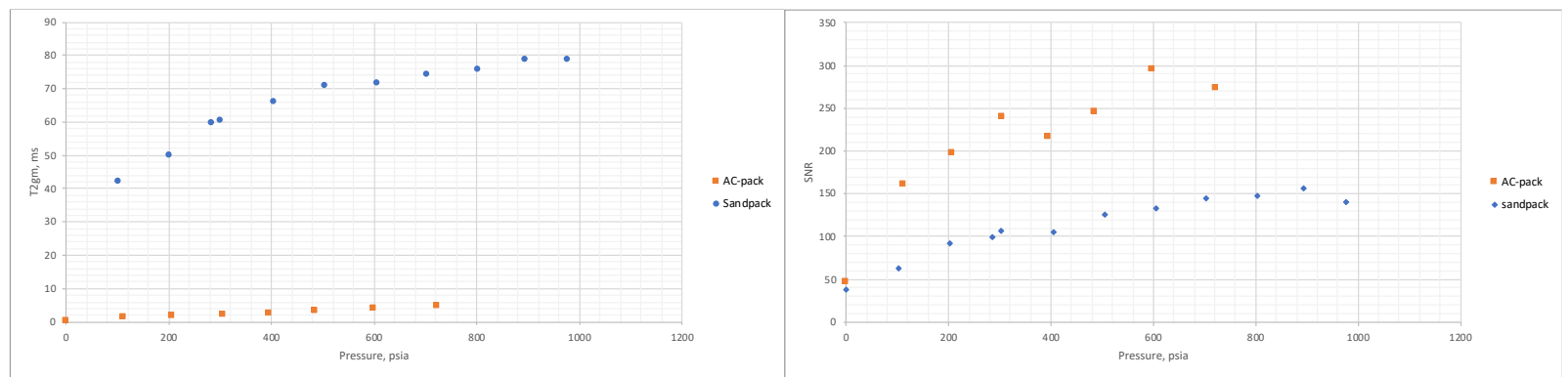

Fig. 3: Left) $\mathrm{T}_{2 \mathrm{gm}}$ of methane in sandpack as a function of pressure in AC and sand packs. Right) SNR versus pressure of methane in $\mathrm{AC}$ and sand packs.

The SNR of methane in sandpack and AC-pack are compared in Figure 6 Right. The SNR in AC-pack is higher than SNR from sandpack. This is because due to adsorbed methane in AC-pack, at each pressure, there is more methane in AC-pack compared to the sandpack, which means more signals and higher SNR.

Figure 7 shows the experimental results of total amplitude versus mass in bulk, sandpack, and AC-pack. As shown in the graph the slope of the total amplitude versus mass in all three cases are matched, which means that methane mass in different porous media can be estimated by the bulk AI.

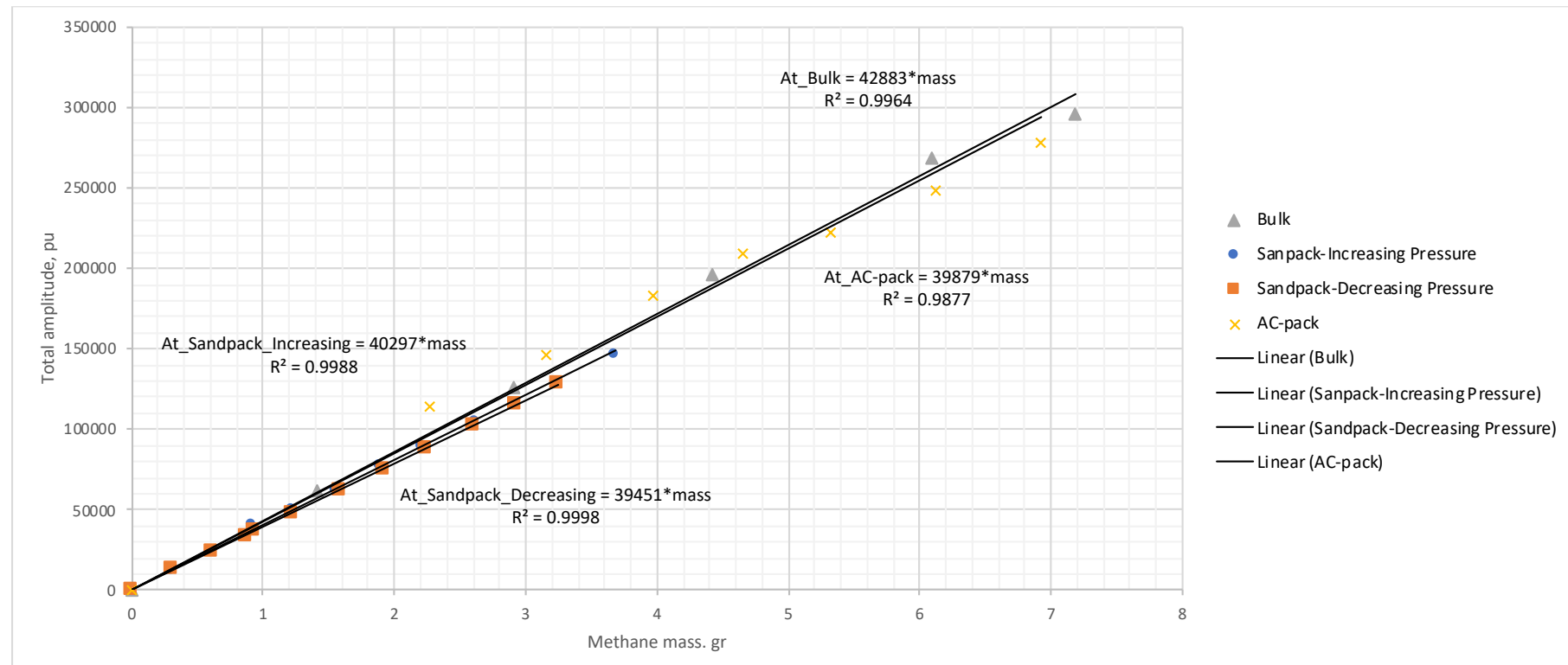

Fig. 4: Total amplitude versus mass of methane in sandpack and AC-pack.

Figure 8 shows the experimental results of total amplitude versus pressure in bulk, sandpack, and AC-pack. The total amplitudes in all porous media are normalized to the pore volume and is used in the calculation of methane adsorption on activated carbon. 


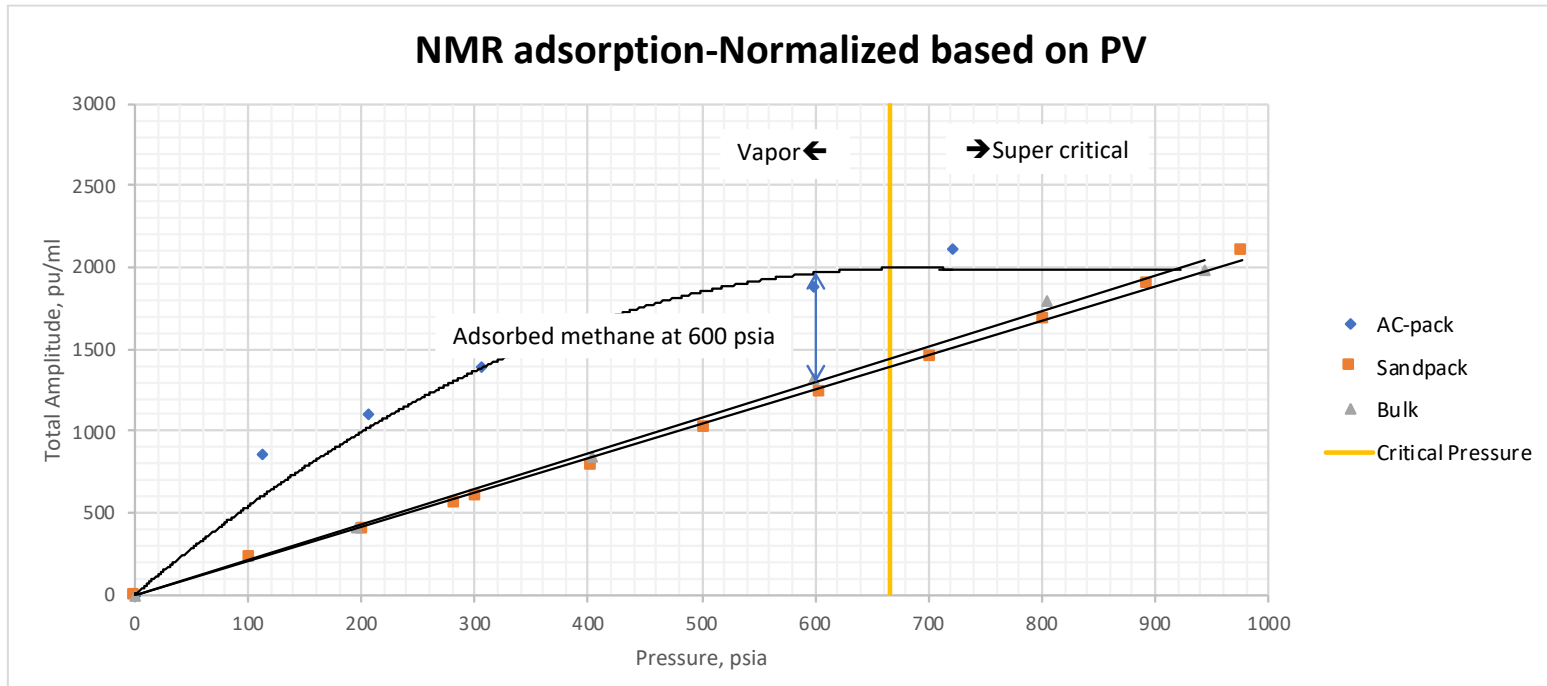

Fig. 5: Quantitative measurement of adsorbed methane on activated carbon at different pressures.

At each pressure, the difference in sandpack/bulk amplitude with the AC-pack is the amplitude of the adsorbed methane. By using the bulk AI, the mass of the adsorbed methane is calculated. The quantified adsorbed methane with respect to methane pressure which is adsorption isotherm of methane on activated carbon is exhibited in Figure 9.

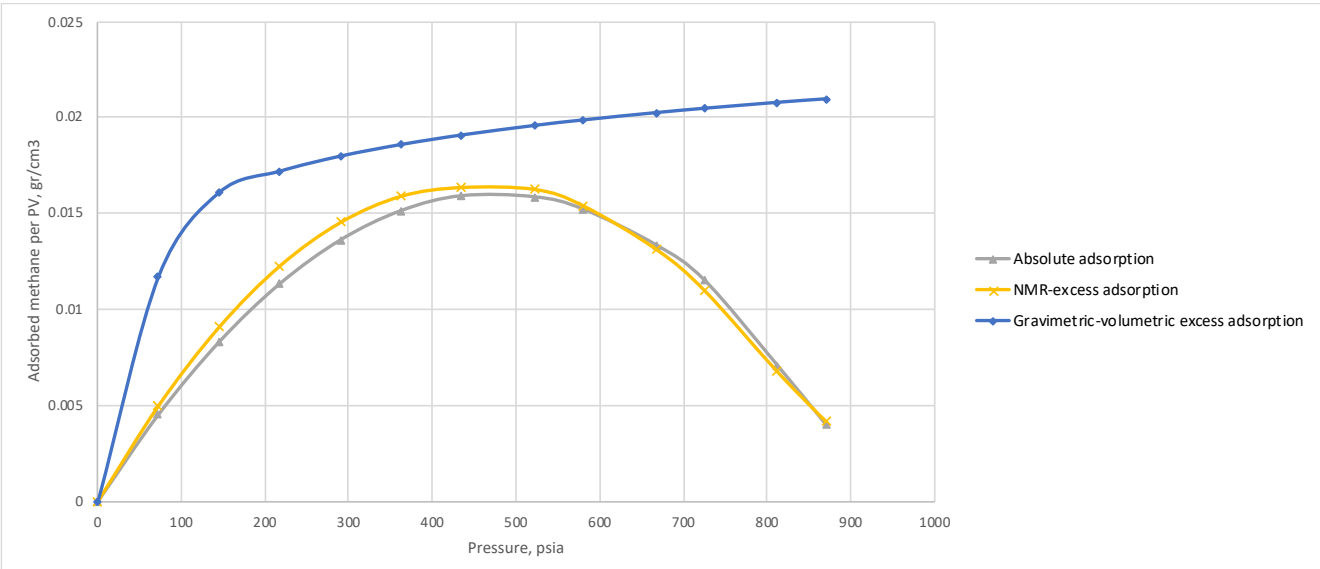

Fig. 6: Adsorption isotherm of methane on activated carbon at room temperature.

To validate the NMR results of adsorption, the gravimetric adsorption is conducted. Figure 10 is the gravimetric mass versus pressure in different porous media. The bulk methane matches the sandpack and the reason is that there is no adsorption of methane in sandpack. The AC-pack line is much higher due to the adsorption of methane in AC-pack. 


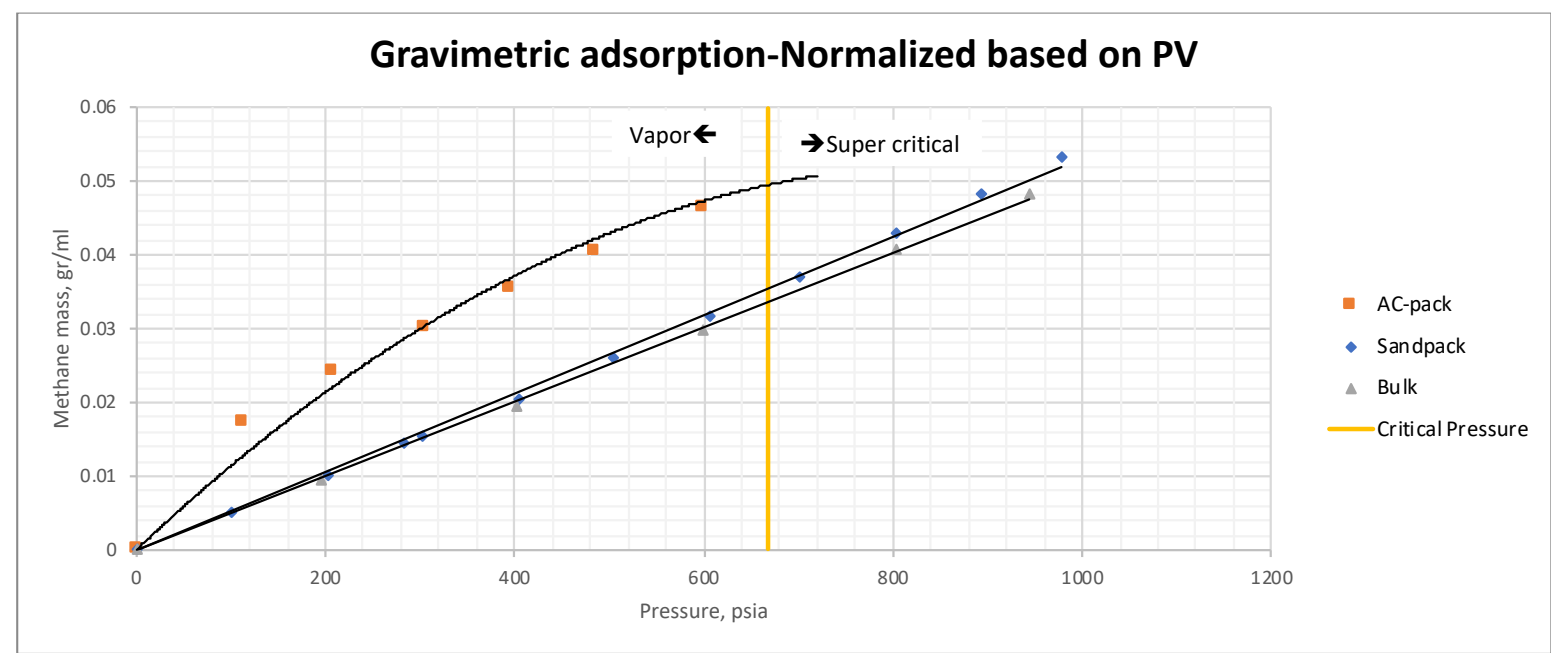

Fig. 7: Gravimetric measurement of adsorbed methane at different pressures.

Figure 11 is a cross plot of adsorbed mass from NMR and mass gravimetric measurements. There is a good match between the two methods of adsorption measurements.

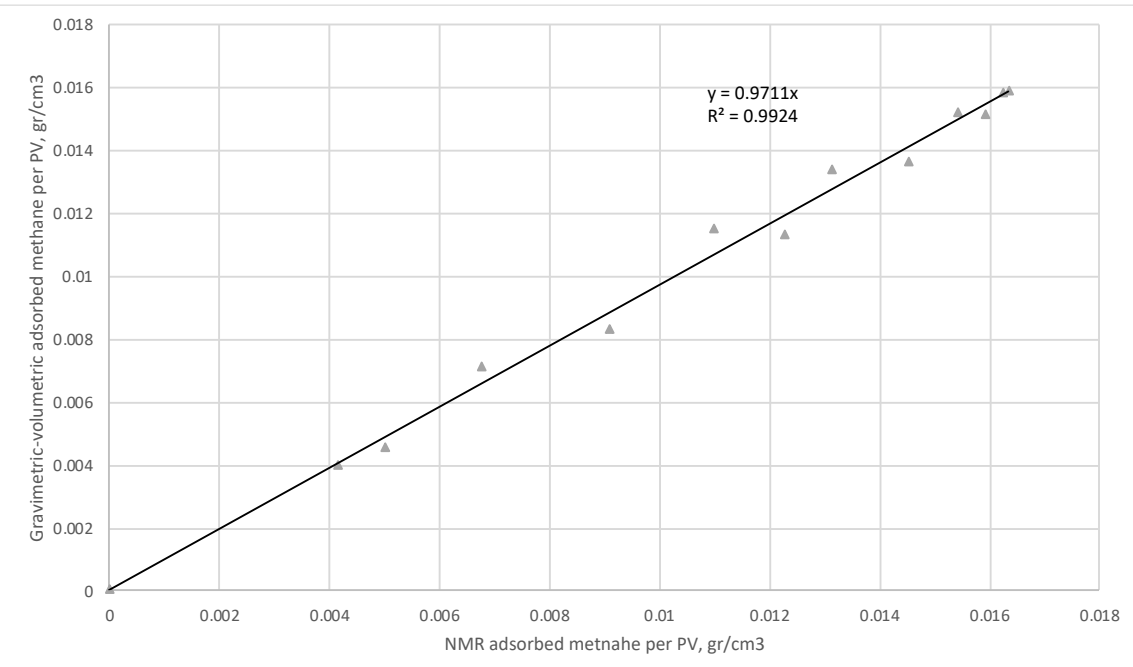

Fig. 8: NMR versus gravimetric adsorption measurements of methane in AC-pack.

Results of two independent methods matches perfectly. Therefore, based on the result of this study, a nondestructive method that developed in this study is able to directly estimate the in-situ gas content of shale reservoirs.

\section{Conclusions}

In this study, Low-Filed NMR with the frequency close to that of the logging tools is used to quantitatively measure methane adsorption and adsorption isotherm in shale mimicking porous media. The main achievements are concluded as follows.

In NMR measurements of gas in sandpack, with increase in pressure, the peaks slower than $10 \mathrm{~ms}$ (peak related to surface relaxivity) shift to the right and peaks faster than $10 \mathrm{~ms}$ (peak related to bulk gas) shift to the left regardless of the type of porous media. 
Gravimetric mean of $\mathrm{T}_{2}$ at each pressure decreases from bulk to sandpack to AC-pack due to effect of pores size and adsorption.

The difference between normalized total $\mathrm{T}_{2}$ amplitude from AC-pack and sandpack/bulk has a positive relationship with with the adsorbed methane, therefore the adsorption isotherm of gaseous hydrocarbons can be directly calculated from single single NMR measurement. Comparing the results of gravimetric and NMR adsorption measurements, it is verified that LowLow-Field NMR with frequency of logging tools is a suitable tool to measure the adsorption of methane in organic porous porous media as well as gaseous pore volume and porosity. The developed method is applicable to estimate the in-situ reserve of gas shales and estimate the maximum adsorbed and free gas at each pressure which improves the gas transport phenomena in shale reservoirs such as gas storage in shale rock, $\mathrm{CO}_{2}$ sequestration, and tight enhanced recoveries.

\section{Acknowledgment}

The authors gratefully acknowledge the support of PERM Inc. and the Schulich School of Engineering (University of Calgary).

\section{References}

[1] A. Papaioannou, R. Kausik, "Methane Storage in Nanoporous Media as Observed via High-Field NMR Relaxometry," Physical Review Applied, vol. 4, 2015.

[2] M. Meng, H. Ge, W. Ji, X. Wang, "Research on the Auto-Removal Mechanism of Shale Aqueous Phase Trapping Using Low Field Nuclear Magnetic Resonance Technique," Journal of Petroleum Science and Engineering, vol. 137, pp. 63-73, 2016.

[3] L. Kaiser, T. Meersmann, J. Logan, A. Pines, "Visulalization of Gas Flow and Diffusion in Porous Media," National Academy of Science, vol. 97, no. 6, 2000.

[4] S. M. Gidcumb, Characterization of Methane Storage in Gas Shales Using NMR. University of North Carolina: Chapel Hill, 2015.

[5] Y. Yao, D. Liu, S. Xie, "Quantitative Characterization of Methane Adsorption on Coal Using a Low-Field NMR Relaxation Method," International Journal of Coal Geology, vol. 131, pp. 32-40, 2014.

[6] J. Liu, Y. Yao, D. Liu, D. Elsworth, "Experimental Evaluation of $\mathrm{CO}_{2}$ Enhanced Recovery of Adsorbed-Gas from Shale," International Journal of Coal Geology, vol. 179, pp. 211-218, 2017.

[7] T. A. Ho, L. Criscenti, Y. Wang, "Nanostructural Control of Methane Release in Kerogen and Its Implications to Wellbore Production Decline," Scientific Reports, vol. 6, pp. 28053, 2016.

[8] R. Heller, M. Zoback, "Adsorption of Methane and Carbon Dioxide on Gas Shale and Pure Mineral Samples," Journal of Unconventional Oil and Gas Resources, vol. 8, pp. 14-24, 2014.

[9] H. Zhao, Z. Lai, A. Firoozabadi, "Sorption Hysteresis of Light Hydrocarbons and Carbon Dioxide in Shale and Kerogen," Scientific Reports, vol. 7, no. 1, pp. 16209, 2017.

[10] I. N. Levine, Physical Chemistry. University of Brooklyn: McGraw-Hill, 1978.

[11] R. Solatpour, J. Bryan, A. Kantzas, "On Estimating Irreducible Water Saturation in Tight Formations Using Nuclear Magnetic Relaxometry," in Proceedings of Calgary SPE Canada Unconventional Resources Conference, Calgary, 2018.

[12] R. Solatpour, A. Kantzas, "Application of Nuclear Magnetic Resonance Permeability Models in Tight Reservoirs," Canadian Journal of Chemical Engineers, 2018.

[13] G. R. Coates, L. Xiao, M. G. Prammer, "NMR Logging Principles and Applications," Halliburton Energy Services, Houston, 1999. 